\title{
“LIGA O VENTILADOR PROFESSOR...”: Uma análise pós-ocupação sobre conforto térmico de um laboratório universitário
}

"TURN ON THE TEACHER FAN...": A post-occupation analysis on thermal comfort in a university laboratory

"ENCIENDA EL VENTILADOR DEL MAESTRO...": Un análisis post-ocupación sobre el confort térmico en un laboratorio universitario

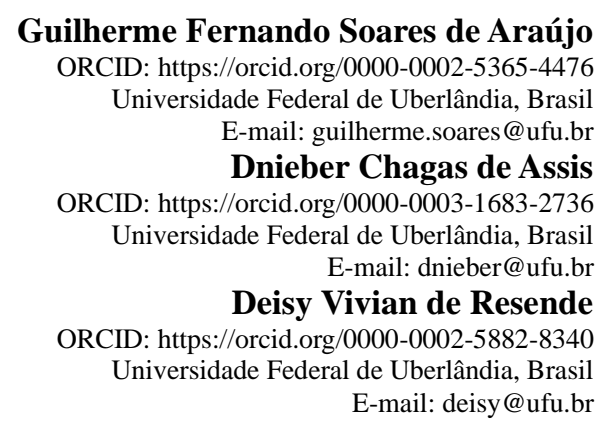

\begin{abstract}
Resumo
Antigamente, no ambiente de trabalho, as pessoas tinham que buscar mecanismos para se adaptarem ao ambiente em que estavam inseridos. Hoje em dia, já existe uma preocupação em fazer modificações nos locais de trabalho para que os mesmos se adaptem aos seus usuários. Sendo assim, se tornou necessário investir em pesquisas sobre o conforto térmico. Portanto, o presente artigo tem como objetivo analisar o conforto térmico em um laboratório nas instalações de uma universidade localizada na região Centro Oeste de Minas Gerais, buscando identificar como a concepção de um espaço pode influenciar na sensação térmica. Os resultados encontrados mostraram que modificações sem análises a priori no ambiente em questão, aumentaram em $20 \%$ os pontos de desconformidade térmica, ficando fora do intervalo de conforto $(-0,82<\mathrm{VME}<0,82)$.
\end{abstract}

Palavras-chave: Conforto térmico; Ambiente de trabalho; Laboratório.

\begin{abstract}
Previously, in the workplace, people had to seek mechanisms to adapt to the environment in which they were inserted. Nowadays there is already a concern to make changes at the workplace in order to adapt to their users. Thus, it became necessary to invest in research on thermal comfort. Therefore, this article aims to analyze the thermal comfort in a laboratory in the facilities of a university located in the Central West of Minas Gerais, seeking to identify how the design of a space could influence the thermal sensation. The results showed that changes without a priori analysis in the environment in question, increased by $20 \%$ points of thermal unconformity, getting out of the comfort range ($0.82<\mathrm{VME}<0.82$ ).
\end{abstract}

Keywords: Thermal comfort; Workplace; Laboratory.

\section{Resumen}

En el pasado, en el ámbito laboral, las personas debían buscar mecanismos para adaptarse al entorno en el que se insertaban. Hoy en día, ya existe una preocupación por realizar cambios en los lugares de trabajo para que se adapten a sus usuarios. Por tanto, se hizo necesario invertir en la investigación sobre el confort térmico. Por tanto, este artículo tiene como objetivo analizar el confort térmico en un laboratorio de las instalaciones de una universidad ubicada en la región Medio Oeste de Minas Gerais, buscando identificar cómo el diseño de un espacio puede influir en la sensación térmica. Los resultados encontrados mostraron que modificaciones sin análisis previo en el ambiente en cuestión, aumentaron los puntos de no conformidad térmica en un $20 \%$, quedando fuera del rango de confort $(-0,82<\mathrm{VME}$ $<0,82)$.

Palabras clave: Confort térmico; Ambiente de trabajo; Laboratorio. 


\section{Introdução}

Ao longo da história do trabalho, o corpo do ser humano foi se adaptando a diversos ambientes laborais e às mudanças que ocorriam no mesmo, criando mecanismos próprios que proporcionassem uma melhor sensação de conforto térmico a estes ambientes. Atualmente diversas atividades são executadas em ambientes fechados que, por sua vez, sendo mal projetados, geram problemas ergonômicos, má iluminação e mau aproveitamento da ventilação natural e artificial (Sevegnani; Filho; Silva, 1994).

Algumas atividades de trabalho estão sujeitas a utilizarem espaços com uma climatização artificialmente construída ou mecanizada, proporcionando um relativo "conforto", para que possam executar suas atividades com o melhor desempenho possível, adequando e relacionando a sensação térmica ao bem-estar no trabalho, expressa pela satisfação com o ambiente organizacional (Leite, 2003; Marangon \& Miolo, 2021).

Devido ao grande número de atividades desenvolvidas em ambientes fechados, tornam-se importantes os estudos de conforto térmico, que buscam oferecer diretrizes que satisfaçam o homem em todos os ambientes (Andreasi, 2009), o que, segundo Batiz et al., (2009), é a busca intuitiva do sentir-se bem natural do homem.

Segundo Frota e Schiffer (2001), sabe-se que o homem tem melhores condições de saúde e desempenho com capacidade máxima quando o organismo funciona sem que ocorra o estresse ou a fadiga térmica, evidenciando a necessidade de desenvolvimento de estudos que abordem o assunto. Enunciam ainda, que é parte do objetivo da arquitetura, proporcionar condições térmicas que sejam compatíveis com o conforto térmico, permitindo que ocorram as trocas de calor entre o corpo humano e o ambiente, sem grande esforço dos indivíduos.

Sendo assim, as pesquisas buscam analisar e estabelecer as condições necessárias para que se avalie e se conceba um ambiente adequado às atividades e ocupações humanas, e também para estabelecer métodos que realizem uma análise térmica mais detalhada. Os estudos baseiam-se na satisfação do homem por estar em um ambiente termicamente confortável, no desempenho humano e também na conservação de energia, devido à mecanização e industrialização da população atual (Angelini \& Júnior, 2020; Lamberts et al., 2011).

Portanto, o seguinte estudo tem como objetivo analisar o conforto térmico em um laboratório nas instalações de uma universidade localizada na região Centro Oeste de Minas Gerais, após a ocupação do espaço, buscando identificar como a concepção pode influenciar na sensação térmica, considerando as ventilações natural e artificial.

De acordo com a American Society of Heating, Refrigeration and Air Conditioning Engineers (ASHRAE) o conforto térmico é o estado da mente que expressa satisfação do homem com o ambiente térmico que o circunda como resultado da combinação satisfatória das temperaturas que o circunda (Lamberts et al., 2014).

Para Ruas (1999), as primeiras considerações para o estabelecimento de critérios de conforto térmico foram feitas no início do século XX. A partir de então, buscou-se entender quais são os fatores que influenciam na sensação térmica e como eles se relacionam. Estudos mostram que o conforto está relacionado com o equilíbrio térmico do corpo humano e que o mesmo envolve fatores pessoais e ambientais.

De acordo com Frota e Schiffer (2001), o bem-estar das pessoas nos ambientes em que estão inseridos depende também do calor induzido por máquinas e equipamentos utilizados durante o processo realizado na atividade de trabalho, da presença de outras pessoas, de iluminação artificial e de calor solar.

Os estudos existentes não são suficientes para adotarmos valores como sendo os adequados para a população de uma forma geral, pois devemos considerar que as pessoas apresentam percepções diferentes e que as sensações são subjetivas. A percepção tem um importante papel por permitir que o indivíduo atribua significados às coisas, ações e feitos (BATIZ et al., 2009). 
Segundo a ISO 7730/94, a combinação dos diversos fatores é o principal determinante da sensação de conforto ou desconforto térmico (Oliveira et al., 2010). Portanto, o bem-estar depende de fatores que interferem no funcionamento do sistema termorregulador; provocando indisposição e insuficiência no trabalho, podem acarretar no aumento da probabilidade de ocorrer acidentes (Ruas, 1999; 2001).

Do ponto de vista do ensino, é importante ressaltar que a atenção tem um papel importante na compreensão e no aprendizado, tornando-se vital analisar fatores que podem interferir, como o calor, barulho, má iluminação, etc. "A atenção é um processo mental que permite com que as pessoas se centrem em um determinado estímulo ou informação relevante" (Batiz et al., 2009). Atua também como um pré-requisito para o funcionamento de processos cognitivos complexos, uma vez que não é possível avaliar a percepção ou qualquer outra atividade mental sem considerar os processos de atenção (Batiz et al., 2009).

De acordo com Wargocki et al. (2005), o aumento da temperatura e a qualidade do ar reduzem o desempenho no ensino, influenciando de forma negativa a capacidade de aprendizado. Identifica-se ainda que muitos estudos não consideram todas as variáveis térmicas, pois muitos avaliam somente a temperatura do ar, o que influencia os resultados dos mesmos (Batiz et. al., 2009). Segundo Lorsch e Abdou (1994, apud Andreasi, 2009) melhores condições térmicas aumentam a produtividade e o desempenho humano.

Como evidenciado anteriormente, algumas variáveis, associadas com a atividade executada, influenciam no nosso conforto térmico, determinando se há conforto ou desconforto. As variáveis se dividem em dois grupos apresentados a seguir: variáveis ambientais e variáveis humanas.

Variáveis ambientais: Temperatura do ar (ta) ou Temperatura de bulbo seco (Tbs): Quando a temperatura é inferior à da pele, ocorre a remoção de calor por convecção. Se a temperatura do ar for superior à da pele, ele cederá calor para o corpo; Temperatura radiante média (trm): É uniforme em um ambiente imaginário no qual a troca de calor por radiação é igual ao ambiente real não uniforme; Umidade relativa (UR): Fornece a quantidade de vapor de água no ar em relação à quantidade máxima que pode conter, a uma determinada temperatura; e Velocidade relativa do ar (vr): A velocidade do ar altera as trocas de calor por convecção e evaporação (Nunes \& Giglio, 2020; Lamberts et al., 2014; Ruas, 1999).

Variáveis humanas: Taxa de metabolismo: É pelo metabolismo que o organismo adquire a energia necessária. A liberação dessa energia varia de acordo com a atividade muscular; Vestimenta utilizada: Impõe uma resistência térmica, como se fosse uma barreira para as trocas de calor, entre o corpo e o meio (Lamberts et al., 2014).

Estabelecida a relação do desconforto térmico, a perda de produtividade dos trabalhadores e a insatisfação com o ambiente de trabalho, tornou-se necessário realizar estudos para estabelecer medidas corretivas e/ou preventivas nos projetos dos espaços de trabalho, buscando uma adaptação às necessidades dos usuários dos mesmos. Os primeiros estudos surgiram na Avaliação Pós-ocupação a partir da década de 70 (Nogueira et. Al., 2005) e mostram que:

Concepções modernas para organização e produção, geradas pela globalização, trouxeram novas preocupações, que se tornaram em novos temas de estudo relacionados ao conforto ambiental, como eficiência energética, saúde ocupacional e produtividade (Lamerts et al.,1997, apud Nogueira; Duarte \& Nogueira, 2005, p.39).

A Avaliação Pós-ocupação (APO) é um processo sistematizado e rigoroso no controle da qualidade em ambientes após algum tempo de sua construção e ocupação, e tem como principal característica a participação dos usuários no processo de análise (Rheingantz et. al., 2006). Os resultados das análises são baseados no cruzamento das informações dos usuários com os laudos técnicos na interpretação das respostas (Filho, 2008).

É também uma metodologia que já é aplicada nos países desenvolvidos e foca nos ocupantes do ambiente e suas necessidades. A partir disso, elaboram-se ideias sobre as consequências do projeto sobre a edificação (Rheingantz; Cosenza \& Lima, 2006). 
Uma prática eficiente no controle da qualidade do ambiente, realimentando os projetos com novas informações e pode ser utilizada para identificar problemas ergonômicos, construtivos, estéticos e de conforto de um ambiente em uso. Isso permite encontrar soluções que possam minimizar os problemas e proporcionar maior conforto aos usuários (Ferraz, 2010).

Segundo Rocha (2007) as pesquisas em APO dão prioridade ao uso, manutenção e operação do espaço sob a perspectiva do usuário, sendo recorrente para avaliação de desempenho de ambientes construídos.

Os princípios gerais da Avaliação Pós-Ocupação englobam duas esferas: a intervenção sobre o ambiente construído, minimizando ou eliminando os problemas levantados e potencializando os aspectos positivos evidenciados pelos usuários, contribuindo para a manutenção e melhoria da qualidade de vida em um dado espaço edificado; a esfera informativa, a partir da confecção de bancos de dados, sistematização de resultados, tendo como base os levantamentos realizados (gráficos, tabelas) (Rocha, 2007, p.9).

Sendo assim, a APO pode ser um método eficiente para o desenvolvimento e processo de um ambiente, a partir do uso de conhecimento prévio sobre as necessidades dos usuários e identificação antecipada dos níveis de satisfação (Kuba et al., 2021; Rheingantz; Cosenza \& Lima, 2006).

\section{Metodologia}

O estudo pode ser descrito como um estudo de caso quantitativo, observacional e de corte transversal (Pereira et al., 2018; Yin, 2015). Foi seguido o modelo de Fanger (apud Ruas, 1999), onde o mesmo criou um Diagrama de Conforto, com o auxílio de computadores, para determinar as várias combinações de variáveis que proporcionam conforto. Para completar a avaliação, foi criado também um critério chamado Voto Médio Estimado (VME), para averiguar o desconforto da população em análise. Esse método classifica o ambiente em sete percepções de sensação diferentes: -3 (muito frio), -2 (frio), -1 (levemente frio), 0 (conforto), +1 (levemente calor), +2 (calor) e +3 (muito calor) (Ruas, 2001).

Devido à complexidade que envolve o cálculo do VME, a ISO 7730 (1994) trás, além da fórmula, um conjunto de tabelas que facilitam a obtenção do mesmo. Isso é possível pela combinação dos diversos fatores ambientais e pessoais, possibilitando a determinação da sensação térmica de determinado grupo (RUAS, 2001).

A norma também mostra como calcular um índice da porcentagem de pessoas insatisfeitas com o ambiente (PPD) e apresenta um gráfico que pode ser utilizado para determiná-lo. A aplicação do método adotado pela norma internacional possibilita verificar se o ambiente se enquadra nas condições aceitáveis de conforto térmico, estabelecer maiores limites de aceitabilidade em ambientes em que isso for possível e fornecer combinações de variáveis que possibilitem a sensação de neutralidade térmica (Lamberts et al., 2011).

Estudos mostram que existiam diferenças na aplicação dos métodos existentes para avaliação de conforto térmico, sendo necessário um fator de correção. Surgiu então um novo modelo proposto por Humphreys e Nicol (2002) e Fanger e Toftum (2002) chamado "método adaptativo" (Andreasi, 2009).

Considerando que as pessoas têm percepções térmicas diferentes, que as sensações são subjetivas e que não é possível agradar 100\% da população em estudo, o valor final do VME deve estar entre -0,82 e 0,82 para dizermos que o ambiente é considerado termicamente confortável para pelo menos $80 \%$ das pessoas presentes no ambiente (RUAS, 1999).

Sendo assim, essas normas buscam fornecer informações, orientações e recomendações sobre como considerar a adaptação de pessoas ao ambiente ao se avaliar e projetar edifícios, sistemas e ambientes de trabalho (Lamberts et al., 2011).

Para aplicação do método e estimar a sensação térmica das pessoas que utilizam o espaço a ser analisado, precisamos (com base na ISO 7730/1994): Definir o local de estudo; Levantar as características do local de estudo; Saber o tipo de vestimenta utilizada; Saber qual tipo de atividade é executado no local em estudo; Dividir a área ocupada em quadrados iguais; 
e Definir os pontos de medição no centro desses quadrados.

Com posse dessas informações, iremos realizar as medições das temperaturas e velocidades relativas do ar. As medições devem ser realizadas a $0,60 \mathrm{~m}$ do piso para pessoas sentadas e a $1,10 \mathrm{~m}$ do piso para pessoas em pé. A medição da temperatura do ar pode ser feita com a utilização de termômetros de mercúrio, termômetros de resistência ou termopares. A temperatura radiante média é medida com a utilização do termômetro de globo (tg) (também pode ser utilizado para medir a temperatura do ar). E a velocidade do ar é medida através do termoanemômetro com capacidade para medir velocidades da ordem de $0,05 \mathrm{~m} / \mathrm{s}$.

Após as medições, precisamos organizar os valores encontrados em uma tabela (Tabela 1) em que as três primeiras colunas contêm os valores encontrados durante as medições. Após o preenchimento das primeiras colunas, calculamos o VME para trm=ta utilizando valores da tabela de grau de atividade física de acordo com a atividade desenvolvida. Para alguns valores de VME é necessário fazer a interpolação linear dupla, para outros basta utilizar o valor estabelecido nas tabelas. Abaixo, as fórmulas de interpolação dupla (iii) utilizada e um modelo de tabela a ser empregada para organização dos cálculos (Ruas, 1999):

Incialmente interpola-se em $z=\bar{f}\left(x_{\tilde{j}-1} v y_{0}\right)$, obtendo a equação (i)

$$
\bar{f}\left(x_{j-1}, y_{c}\right)=f\left(x_{j-1}, y_{i-1}\right)+\frac{y_{c}-y_{i-1}}{y_{i}-y_{i-1}}\left[f\left(x_{j-1}, y_{i}\right)-f\left(x_{j-1} v y_{i-1}\right)\right] \text { (i) }
$$

Posteriormente, deve se interpolar em $z=\bar{f}\left(x_{j}, y_{e}\right)$, obtendo a equação (ii)

$$
\bar{f}\left(x_{j}, y_{i}\right)=f\left(x_{j}, y_{i-1}\right)+\frac{y_{i}-y_{i-1}}{y_{i}-y_{i-1}}\left[f\left(x_{j}, y_{i}\right)-f\left(x_{j}, y_{i-1}\right)\right]
$$

Finalmente, associando-se as equações (i) e (ii), se obtêm a interpolação linear dupla em $z=\bar{f}\left(x_{v}, y_{c}\right)$.

$$
\bar{f}\left(x_{e}, y_{c}\right)=\bar{f}\left(x_{j-1}, y_{c}\right)+\frac{x_{i}-x_{j-1}}{x_{i}-x_{i}-1}\left[\bar{f}\left(x_{j}, y_{c}\right)-\bar{f}\left(x_{\tilde{j}-1}, y_{c}\right)\right] \text { (iii) }
$$

Tabela 1 - Tabela utilizada para o registro dos dados de campo.

\begin{tabular}{cccccccc}
\hline & 1 & 2 & 3 & 4 & 5 & 6 & 7 \\
\hline $\begin{array}{c}\text { Pontos } \\
\text { de } \\
\text { medida }\end{array}$ & $t_{\alpha}$ & $\Delta t$ & $v_{r}$ & VME & $\Delta V M E /{ }^{\circ} \mathrm{C}$ & $\Delta V M E$ & $V M E_{r e a l}$ \\
& $\left({ }^{\circ} \mathrm{C}\right)$ & $t r m-t_{\alpha}$ & $(\mathrm{m} / \mathrm{s})$ & $t r m=t_{\alpha}$ & $\operatorname{trm}$ & $(2 \times 5)$ & $(4+6)$ \\
& & $\left({ }^{\circ} \mathrm{C}\right)$ & & & $\left({ }^{\circ} \mathrm{C}^{-1}\right)$ & & \\
\hline
\end{tabular}

Fonte: Ruas (1999).

Como os valores de VME correspondem à condição em que trm=ta, é necessário realizarmos a correção dos mesmos. Para essa correção precisamos dos valores obtidos dos gráficos $\Delta \mathrm{VME} /{ }^{\circ} \mathrm{C}$ trm estabelecidos pela norma para o tipo de atividade em estudo, em função do isolamento térmico da roupa e da velocidade do ar $(\mathrm{m} / \mathrm{s})$. Com esses valores nós preenchemos a coluna 5 do quadro e, assim, realizamos os cálculos da primeira correção multiplicando a coluna 2 pela coluna 5 e o resultado se encontra na coluna 6. Finalizando a correção para encontrarmos o 『VME】_real, somamos os valores da coluna 4 (valores inicialmente obtidos) com os valores da coluna 6 e preenchemos a coluna 7 com os resultados. 
Como definido pela FUNDACENTRO, os valores obtidos na coluna 7 são analisados para verificar se os mesmos se encontram entre $-0,82$ e 0,82 , que são os valores considerados ideais para o conforto térmico de pelo menos $80 \%$ das pessoas do recinto. Com base nos resultados iremos avaliar se o ambiente apresenta condições de conforto térmico ou se precisamos realizar modificações para que o conforto seja alcançado.

\section{Resultados e Discussão}

O primeiro passo foi determinar o local em que as medições seriam realizadas. Em conversas informais com alguns professores, foi indicado realizá-las em um laboratório de Hidráulica e Pneumática. O espaço em estudo foi confeccionado em alvenaria, não possui janelas, possui apenas uma porta e, máquinas e equipamentos que emitem calor e ruído durante o funcionamento. Estabeleceu-se através de análise que a atividade do funcionário é caracterizada como sedentária $\left(58 \mathrm{~W} / \mathrm{m}^{\wedge} 2\right.$ 1 met) e isolamento térmico de roupas leves (0,5 clo) (Lamberts et al., 2011; Ruas, 1999, p. 16-30).

Dividiu-se então o espaço em 10 pontos uniformes distintos para fazer as medições de temperatura e velocidade do ar, no período da tarde entre às $14 \mathrm{~h}$ e $17 \mathrm{~h}$, com a utilização de um termo anemômetro digital Modelo TAFR-180 e um termômetro de globo Modelo TGD-400. O procedimento foi realizado duas vezes, uma com a porta aberta e outra com a porta aberta e o ventilador ligado (condições frequentes de uso segundo os ocupantes do local).

Abaixo apresenta-se um croqui do laboratório com os pontos demarcados e duas tabelas (Tabela 2 e 3 ) com os dados coletados durante a medição.

Tabela 2 - Coleta de dados com a porta aberta.

\begin{tabular}{cccc}
\hline Pontos de coleta & $\begin{array}{c}\text { Temperatura de Globo } \\
\left({ }^{\circ} \mathbf{C}\right)\end{array}$ & $\begin{array}{c}\text { Temperatura do ar } \\
\text { Ambiente }\left({ }^{\circ} \mathbf{C}\right)\end{array}$ & Velocidade do ar $(\mathbf{m} / \mathbf{s})$ \\
\hline $\mathbf{1}$ & 21,80 & 26,90 & 0,00 \\
$\mathbf{2}$ & 21,60 & 26,70 & 0,00 \\
$\mathbf{3}$ & 21,60 & 26,90 & 0,00 \\
$\mathbf{4}$ & 21,50 & 26,50 & 0,00 \\
$\mathbf{5}$ & 21,10 & 25,70 & 0,00 \\
$\mathbf{6}$ & 21,60 & 26,80 & 0,10 \\
$\mathbf{7}$ & 21,50 & 26,60 & 0,10 \\
$\mathbf{8}$ & 21,60 & 26,80 & 0,40 \\
$\mathbf{9}$ & 21,20 & 26,00 & 0,00 \\
$\mathbf{1 0}$ & 21,30 & 26,10 & 0,00 \\
\hline
\end{tabular}

Fonte: Autores.

Tabela 3 - Coleta de dados com a porta aberta e ventilador ligado.

\begin{tabular}{cccc}
\hline Pontos de coleta & $\begin{array}{c}\text { Temperatura de Globo } \\
\left({ }^{\circ} \mathbf{C}\right)\end{array}$ & $\begin{array}{c}\text { Temperatura do ar } \\
\text { Ambiente }\left({ }^{\circ} \mathbf{C}\right)\end{array}$ & Velocidade do ar $(\mathbf{m} / \mathbf{s})$ \\
\hline $\mathbf{1}$ & 22,00 & 26,90 & 0,30 \\
$\mathbf{2}$ & 21,90 & 26,80 & 0,10 \\
$\mathbf{3}$ & 21,90 & 26,90 & 0,20 \\
$\mathbf{4}$ & 21,90 & 26,80 & 0,20 \\
$\mathbf{5}$ & 21,90 & 26,90 & 0,10 \\
$\mathbf{6}$ & 21,90 & 26,90 & 0,40 \\
$\mathbf{7}$ & 22,10 & 26,80 & 0,10 \\
$\mathbf{8}$ & 22,30 & 26,90 & 0,50 \\
$\mathbf{9}$ & 22,00 & 26,80 & 0,40 \\
$\mathbf{1 0}$ & 21,90 & 27,00 & 0,10 \\
\hline
\end{tabular}

Fonte: Autores. 
Após a coleta de dados pôde-se realizar os cálculos para que se chegasse aos parâmetros necessários de quais medidas de controle deveriam ser adotadas no ambiente de trabalho (Tabelas 4 e 5). Os cálculos foram feitos com auxílio do programa Excel e a tabela abaixo apresenta os resultados finais obtidos para ambas as situações.

Tabela 4 - Resultados finais com a porta aberta.

\begin{tabular}{|c|c|c|c|c|c|c|c|}
\hline & 1 & 2 & 3 & 4 & 5 & 6 & 7 \\
\hline $\begin{array}{l}\text { Pontos } \\
\text { de } \\
\text { medida }\end{array}$ & $\begin{array}{c}t_{a} \\
\left({ }^{\circ} \mathrm{C}\right)\end{array}$ & $\begin{array}{c}\Delta t \\
\operatorname{trm}-t_{\alpha} \\
\left({ }^{\circ} \mathrm{C}\right)\end{array}$ & $\begin{array}{c}v_{r} \\
(\mathrm{~m} / \mathrm{s})\end{array}$ & $\begin{array}{c}\text { VME } \\
\operatorname{trm}=t_{\alpha}\end{array}$ & $\begin{array}{c}\Delta V M E / P \mathrm{C} \\
\operatorname{trm} \\
\left({ }^{\circ} \mathrm{C}^{-1}\right)\end{array}$ & $\begin{array}{c}\triangle V M E \\
(2 \times 5)\end{array}$ & $\begin{array}{c}V_{\text {real }} \\
(4+6)\end{array}$ \\
\hline 1 & 26,90 & $-5,10$ & 0,00 & 0,38 & 0,17 & $-0,87$ & $-0,48$ \\
\hline 2 & 26,70 & $-5,10$ & 0,00 & 0,31 & 0,17 & $-0,87$ & $-0,56$ \\
\hline 3 & 26,90 & $-5,30$ & 0,00 & 0,38 & 0,17 & $-0,90$ & $-0,52$ \\
\hline 4 & 26,50 & $-5,00$ & 0,00 & 0,23 & 0,17 & $-0,85$ & $-0,62$ \\
\hline 5 & 25,70 & $-4,60$ & 0,00 & $-0,07$ & 0,17 & $-0,78$ & $\underline{-0,86}$ \\
\hline 6 & 26,80 & $-5,20$ & 0,10 & 0,28 & 0,16 & $-0,83$ & $-0,55$ \\
\hline 7 & 26,60 & $-5,10$ & 0,10 & 0,21 & 0,16 & $-0,82$ & $-0,61$ \\
\hline 8 & 26,80 & $-5,20$ & 0,40 & $-0,31$ & 0,14 & $-0,73$ & $-1,04$ \\
\hline 9 & 26,00 & $-4,80$ & 0,00 & 0,04 & 0,17 & $-0,82$ & $\overline{-0,78}$ \\
\hline 10 & 26,10 & $-4,80$ & 0,00 & 0,08 & 0,17 & $-0,82$ & $-0,73$ \\
\hline
\end{tabular}

Fonte: Autores.

Tabela 5 - Resultados finais com a porta aberta e ventilador ligado.

\begin{tabular}{|c|c|c|c|c|c|c|c|}
\hline & 1 & 2 & 3 & 4 & 5 & 6 & 7 \\
\hline $\begin{array}{l}\text { Pontos } \\
\text { de } \\
\text { medida }\end{array}$ & $\begin{array}{c}t_{a} \\
\left({ }^{\circ} \mathrm{C}\right)\end{array}$ & $\begin{array}{c}\Delta t \\
\operatorname{trm}-t_{\alpha} \\
\left({ }^{\circ} \mathrm{C}\right)\end{array}$ & $\begin{array}{c}v_{r} \\
(\mathbf{m} / \mathbf{s})\end{array}$ & $\begin{array}{c}\mathrm{VME} \\
\operatorname{trm}=t_{\alpha}\end{array}$ & $\begin{array}{c}\Delta V M E /{ }^{\circ} \mathrm{C} \\
\operatorname{trm} \\
\left({ }^{\circ} \mathrm{C}^{-1}\right)\end{array}$ & $\begin{array}{c}\Delta V M E \\
(2 \times 5)\end{array}$ & $\begin{array}{c}V M E_{\text {real }} \\
(4+6)\end{array}$ \\
\hline 1 & 26,90 & $-4,90$ & 0,30 & $-0,12$ & 0,15 & $-0,73$ & $\underline{-0,85}$ \\
\hline 2 & 26,80 & $-4,90$ & 0,10 & 0,28 & 0,16 & $-0,78$ & $-0,51$ \\
\hline 3 & 26,90 & $-5,00$ & 0,20 & 0,05 & 0,15 & $-0,76$ & $-0,71$ \\
\hline 4 & 26,80 & $-4,90$ & 0,20 & 0,01 & 0,15 & $-0,74$ & $-0,73$ \\
\hline 5 & 26,90 & $-5,00$ & 0,10 & 0,31 & 0,16 & $-0,80$ & $-0,49$ \\
\hline 6 & 26,90 & $-5,00$ & 0,40 & $-0,26$ & 0,14 & $-0,70$ & $\underline{-0,96}$ \\
\hline 7 & 26,80 & $-4,70$ & 0,10 & 0,28 & 0,16 & $-0,75$ & $-0,47$ \\
\hline 8 & 26,90 & $-4,60$ & 0,50 & $-0,37$ & 0,14 & $-0,62$ & $-1,00$ \\
\hline 9 & 26,80 & $-4,80$ & 0,40 & $-0,31$ & 0,14 & $-0,67$ & $-0,98$ \\
\hline 10 & 27,00 & $-5,10$ & 0,10 & 0,36 & 0,16 & $-0,82$ & $\overline{-0,47}$ \\
\hline
\end{tabular}

Fonte: Autores.

De acordo com os valores encontrados, percebemos que dois dos dez pontos avaliados na primeira análise (ambiente sem ventilador) apresentam valores fora do limite adequado $(-0,82<\mathrm{VME}<0,82)$ de conforto térmico, representando $20 \%$ do total.

$\mathrm{Na}$ segunda situação analisada, apesar do ambiente ter ventilador, nota-se que quatro dos dez pontos apresentam desconformidade com o limite especificado $(-0,82<\mathrm{VME}<0,82)$, representando $40 \%$ do total.

O resultado aparentemente contraditório demonstra a ineficácia de se aplicar uma metodologia de controle de conforto térmico, sem análise aprofundada a priori, pois a modificação adotada pode piorar a situação ao invés de melhorá-la. Fato evidenciado pela piora do ambiente com o ventilador ligado, correspondendo a um aumento de $20 \%$ dos pontos de desconformidade, da primeira para a segunda situação.

Vale ressaltar que as medições ocorreram durante o Outono, período em que as temperaturas estão mais amenas em 
algumas localidades. E, também, que o desconforto pode se dar devido a baixas temperaturas. Fato corroborado pela ultrapassagem do limite inferior de contorto (VME<-0,82).

Os resultados obtidos indicam que o sistema de ventilação existente não é eficaz para manter o conforto térmico em todos os pontos do ambiente, sendo necessário adotar medidas de controle para reverter os dados em desconformidade. A adoção dessas medidas deve ser feita através de estudos futuros que definam um sistema de ventilação que seja capaz de proporcionar um conforto térmico nesses pontos sem que cause alguma perturbação nos pontos que já atendam os quesitos de satisfação térmica.

Justifica-se também a necessidade de melhorias tomando como base legal o que está estabelecido na NR 17, que exige que as condições ambientais de trabalho devam estar adequadas as características psicofisiológicas dos trabalhadores e a natureza do trabalho a ser realizado evitando assim que haja o tanto desconforto como a perda de produtividade (Maas et al., 2020).

No intuito de buscar alternativas para resolver as desconformidades, podemos sugerir algumas possíveis soluções. Como por exemplo, a instalação de janelas no ambiente para poder aproveitar a ventilação natural, e como vimos que o ventilador presente não é totalmente eficaz, podemos instalar ventiladores de teto, com regulagem de velocidade, para que a ventilação seja uniforme em todo o ambiente e oferecendo opções para dias mais quentes e dias mais frios.

Devemos lembrar ainda que qualquer modificação a ser realizada deve passar por estudos de validação para verificar a eficiência das mesmas, buscando sempre zelar pela melhor condição ambiental para seus funcionários e todos os usuários do ambiente.

\section{Conclusão}

O presente estudo se ateve em atender ao objetivo inicial, avaliar o conforto térmico de um ambiente, buscando identificar como a concepção do espaço pode influenciar na sensação térmica e possíveis medidas a serem consideradas para obtenção de um ambiente melhor para seus usuários.

Verificamos que, apesar das medições não terem ocorrido no período mais quente do ano, obtemos um número significativo de valores em desconformidade. Isso se deu pelo fato de que a desconformidade também ocorre quando há baixas temperaturas. Na primeira situação obtemos dois pontos desconformes e na segunda foram quatro pontos, o que mostra que a modificação feita (inserção do ventilador) não é eficiente para controlar a desconformidade. Um dos pontos inicialmente desconforme (ponto 5) passou a estar conforme, porém outros pontos passaram a estar desconforme.

Os dados mostram ainda que a situação poderia ser mais crítica, devido à concepção do ambiente e se o estudo tivesse sido realizado em períodos mais quentes ou mais frios, em situações extremas. Podemos afirmar que o local precisa de ajustes, sendo assim, propusemos algumas modificações a serem realizadas, mas que precisam passar por validação em estudos futuros para que possamos verificar a viabilidade de tais ajustes.

A fim de complementar o estudo e a motivo de comparação, poderíamos ter realizado medições em diferentes épocas do ano. Durante o Verão, de calor intenso na região, durante o Outono como foi realizado (período de transição) e também durante o Inverno, com baixas temperaturas. Seria importante para verificarmos como o ambiente se comporta sob diferentes temperaturas e situações, até mesmo para verificar se as modificações sugeridas seriam eficientes para todo o ano.

Como vimos anteriormente, o conforto ou desconforto dos usuários de um ambiente pode influenciar no rendimento e na satisfação com o trabalho, de uma forma negativa ou positiva. Em caso de aumento da satisfação, podemos, por consequência, aumentar o rendimento, reduzir custos da produção, absenteísmo e rotatividade e aumentar a qualidade dos produtos. No caso da educação, proporcionar conforto térmico significa aumentar a capacidade de concentração na maioria dos 
alunos, aumentando os seus rendimentos e interesse pelos assuntos discutidos em sala de aula. Todos esses fatores nos mostram a importância e justificativa de investimentos em conforto térmico.

\section{Referências}

Andreasi, W. A. (2009). Método para avaliação de conforto térmico em região de clima quente e úmido do Brasil.

Angelini, P. C. B., \& Júnior, J. C. U. U. (2020). Conforto térmico em ambiente escolar na cidade de Cuiabá-MT. Brazilian Geographical Journal, 11(1), 145176.

Batiz, E. C. et al. (2009). Avaliação do conforto térmico no aprendizado: estudo de caso sobre influência na atenção e memória. Produção, 19(3), 477-488.

Ferraz, E. O. (2010). Avaliação pós ocupação: estudo de caso em condomínio habitacional na cidade de Feira de Santana. 2010. 84p. MonografiaUniversidade Estadual De Feira De Santana Departamento De Tecnologia Colegiado De Engenharia, Feira de Santana.

Filho, E. D. F. M. (2008). Avaliação Pós Ocupação com Ênfase em Conforto Ambiental em Edifício Residencial projetado pelo Arq. Niemeyer: o Caso do edifício Montreal em São Paulo - SP.

Frota, A. B., \& Schiffer, S. R. (2001). Manual de Conforto Térmico. (5a ed.), Studio Nobel.

Lamberts, R., Xavier, A. A., Goulart, S., \& Vecchi, R. D. (2011). Conforto e stress térmico. LabEEE, UFSC.

Lamberts, R., Ghisi, E., \& PAPST, A. L. (2000). Desempenho térmico de edificações. Universidade Federal.

Leite, B. C. C. (2003). Sistema de Ar Condicionado com Insuflamento pelo piso em ambientes de escritórios: avaliação do conforto térmico e condições de operação.

Maas, L., Malvestiti, R., Merino, E. A. D., \& Gontijo, L. A. (2020). Norma Regulamentadora 17: considerações para sua revisão. Human Factors in Design, 9(17), 137-162.

Marangon, L., \& Miolo, S. L. G. (2021). Análise Do Conforto Térmico Em Sala De Aula De Escola Em Trindade Do Sul Sc. Seminário de Iniciação Científica e Seminário Integrado de Ensino, Pesquisa e Extensão, e28828-e28828.

Nogueira, M. C. D. J. A., Duarte, L. C., \& Nogueira, J. D. S. (2005). Conforto Térmico na Escola Pública em Cuiabá - MT: Estudo de Caso. Rev. eletrônica Mestr. Educ. Ambient., p. ISSN 1517-1256, Volume 14.

Nunes, G. H., \& Giglio, T. G. F. (2020). Influência das mudanças climáticas no desempenho térmico de uma habitação com diferentes sistemas construtivos: análise do clima de São Paulo. Revista Principia - Divulgação Científica do IFPB, 48, 46-61.

Oliveira, G. S. J. F. D. et al. (2010). Conforto térmico no ambiente de trabalho: avaliação das variáveis subjetivas da percepção do calor. VII Simpósio de Excelência em Gestão e Tecnologia.

Pereira, A. S., Shitsuka, D. M., Parreira, F. J., \& Shitsuka, R. (2018). Metodologia da pesquisa científica. UFSM. https://repositorio.ufsm. br/bitstream/handle/1/15824/Lic_Computacao_Metodologia-Pesquisa-Cientifica.pdf.

Perissinotto, M. et al. (2009). Conforto térmico de bovinos leiteiros confinados em clima subtropical e mediterrâneo pela análise de parâmetros fisiológicos utilizando a teoria dos conjuntos fuzzy. Ciência Rural, 39(5), 1492-1498.

Rheingantz, P. A., Cosenza, C. A., \& Lima, H. C. E. F. R. (2006). Avaliação pós-ocupação.

Rocha, M. V. M. (2007). Avaliação pós-ocupação de edifício institucional estruturado em aço. O caso da sede da prefeitura municipal de Mariana, MG.

Ruas, Á. C. (1999). Conforto Térmico nos Ambiente de Trabalho. FUNDACENTRO.

Ruas, Á. C. (2001). Avaliação de Conforto Térmico: Contribuição à aplicação prática das normas internacionais.

Sevegnani, K. B., Filho, H. G., \& Silva, I. J. O. D. (1994). Comparação de vários materiais de cobertura através de índices de conforto térmico. Scientia Agricola, 51, 01-07.

Wargocki, P. et al. (2005). The effects of classroom air temperature and outdoor air supply rate on performance of school work by children. Proceedings of Indoor Air 2005, the 10th International Conference on Indoor Air Quality and Climate. Beijing: 368-372.

Yin, R. K. (2015). Estudo de Caso: Planejamento e métodos. Bookman editora.

Kuba, J. C., Bogo, A. J., \& Vieira, M. (2021). Avaliação funcional e de conforto térmico em edifícios verticais em Blumenau SC. HOLOS, 3 , 1-22. 